\title{
Investigation of the Effect of the Force-Frequency on the Behaviour of a New Viscous Damper for Railway Applications
}

\author{
Yousif Badri \\ yousif.badri@qu.edu.qa \\ Department of Mechanical and Industrial Engineering, Qatar University, Doha, Qatar \\ Mohammed Hussein \\ mhussein@qu.edu.qa \\ Department of Civil and Architectural Engineering, Qatar University, Doha, Qatar \\ Sadok Sassi \\ sadok.sassi@qu.edu.qa \\ Department of Mechanical and Industrial Engineering, Qatar University, Doha, Qatar \\ Jamil Renno \\ Jamil.Renno@qu.edu.qa \\ Department of Mechanical and Industrial Engineering, Qatar University, Doha, Qatar
}

\begin{abstract}
The primary purpose of this work is to experimentally investigate the damping coefficient of a viscous damper, intended to be used in railway applications to reduce noise emission. The viscous shock absorber used in this study is a commercial vehicle damper to which minor modifications were added. This investigation was focused on detecting the variation in the damping coefficient value over a wide range of frequencies. The experimental setup tends to simulate the railway vibration represented by a strong steel metal sheet structure attached to a shaker from its lower side. The shaker itself is connected to the damper rod through a dual acceleration-force sensor. A sinusoidal load with wide range of frequencies was applied by the shaker to the top of the damper's rod. Both acceleration and force time-responses were collected, stored and analyzed to extract the Force-Displacement and the Force-Velocity graphs. Based on the damping coefficients obtained for the different values of excitation frequencies, the results show that the damping coefficient is not constant and depends on the excitation frequency.
\end{abstract}

Keywords: Damping coefficient; Excitation frequency; Force Vs Velocity; Suspension systems; Transmission oil; Viscous damper

\section{INTRODUCTION}

A suspension system represents a critical element, whether dealing with automobiles, power transmissions, building, or rail tracks. It is used to prevent discomfort damage, outright structural failure, and even noise (Li \& Darby, 2006). A viscous damper usually consists of a cylinder filled with hydraulic oil and separated into two chambers by a piston, itself attached to a moving rod. The movement of the piston in compression or rebound forces the oil to move back and forth through a set of annular orifices on the piston head. This forced passage of oil, which comes from the pressure difference between the two chambers, dissipates the energy of vibration due to the head-loss (Agrawal \& Amjadian, 2015).

Many authors have shown how the use of dampers, with a variety of shapes and 
designs, could enhance the dynamic stability of structures and minimize their vibration motions. In automotive industry, for example, the viscous damper is mainly used to reduce the vertical oscillations and to maintain handling and ride features to an optimal predefined level. Another promising application of viscous dampers is for railway systems. Kaewunruen \& Remennikov (2008) investigated the railway track component dynamic properties. Both the superstructure and substructure of the rail parts generated vibration due to the movement of the rain on the track. Rail pads are usually responsible for reducing the high-frequency forces and transferring the stress from all the rail parts to the sleepers. The modal testing of the previous work showed that the track resonant frequencies are within $40 \mathrm{~Hz}$ and $1500 \mathrm{~Hz}$ for the three modes. Also, (Rådeström et al., 2017) provided a full study for implementing fluid damper to reduce the vibration of railway bridges. They generate a model for the bridge sustaining the HSLM-train. Dellner damper was used as a proposed suspension system for the railway bridge. The specification table of the damper showed different damping coefficient values (C) for each stroke length of the piston damper and applied force. Each damping coefficient value was separately implemented in the bridge model to choose the best damping value. Rådeström et al. (2017) did not mention the effect of changing the force excitation frequency on the damping value. The previous gap of knowledge represented a starting point for this work.

Changing the force excitation frequency is a common procedure for the experimental investigation of viscous dampers. G R Iglesias et al. (2014) investigated the behavior of magnetorheological (MR) fluid damper under different force frequencies with changing the current value that excites the damper fluid. The range of frequencies for the previous study started from 1.5 to $12 \mathrm{~Hz}$. It showed that increasing the force-frequency increases the damping coefficient value.

\section{EXPERIMENTAL SETUP}

The dynamic testing of a viscous damper requires the use of a conventional axial fatigue machine or, in some applications, a specific damper testing machine. In the absence of such equipment, one should look for a convenient way to move the rod of the damper and collect the generated data. In the present investigation, the experimental setup consisted of a viscous damper, for everyday automotive use, attached to a metallic structure. The metallic frame is attached to a shaker on its base support. The shaker moving stinger is connected to the piston rod through a small metallic coupling device. A force-acceleration sensor is attached between the piston rod and the shaker stringer to report both acceleration and force.

\subsection{Structure and damper design}

At the earliest stages of the present study, a Toyota Landcruiser 2006 commercial shock absorber was chosen. The maneuver of the damper showed an excessive stiffness of the rod because of the internal pressure and the viscosity of the oil. To allow manual handling in the lab, we had to empty it from its original oil and fill it with a low viscosity one. Hydraulic Toyota transmission oil PT088-86806-06ATF was found to be an appropriate substitution for the damper original oil. The most important physical properties of the steering oil are illustrated below in Table 1 (Kemp \& Linden, 1990). 
Table 1: Physical properties of transmission oil ATF

\begin{tabular}{|c|c|}
\hline Property & Value \\
\hline Specific Heat, J/kg.K & 2010 \\
\hline Density, g/cm 3 & 0.8530 \\
\hline Kinematic Viscosity, mm2/s & 33.87 \\
\hline Specific Gravity & 0.855 \\
\hline Copper Corrosion Rating & 48 (ASN D 130) \\
\hline
\end{tabular}

The supporting structure (Fig. 1) is a metallic carbon steel frame, made from $1 \mathrm{~cm}$ thick plates. The 3D structure design was conducted by using SolidWorks 3D software then exported to a water jet cutting machine to provide the exact dimensions.

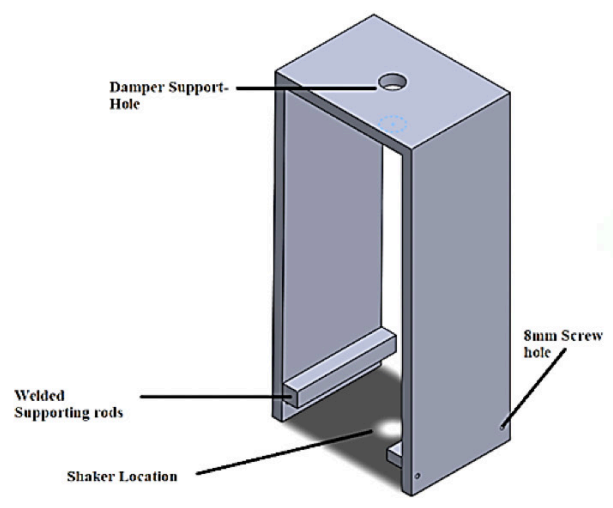

Figure 1: Metallic support for the damper and the shaker

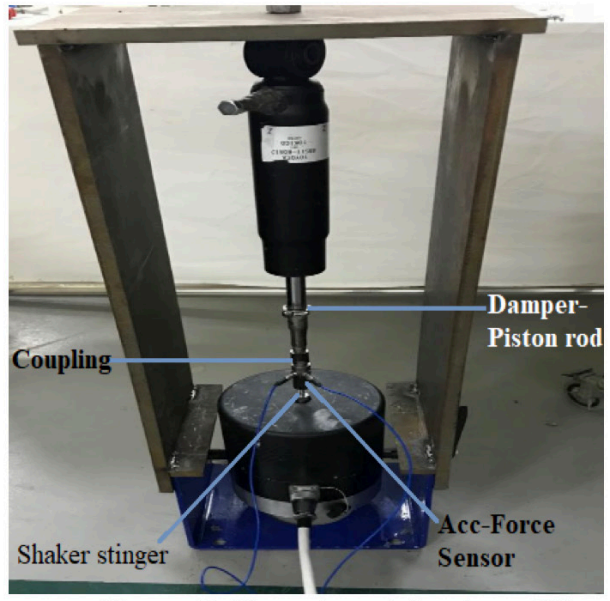

Figure 2: Experimental setup of the viscous damper attached to the shaker

\subsection{Shaker test setup}

For dynamic testing of mechanical structures, we need an excitation source, a device to measure the response, and a digital signal processor to analyze the system response. In this experiment, the excitation source is represented by a signal generator and a shaker, Model 2100E11 TMS, with maximum output force 440-N. To secure a stable position of the damper, its body was mounted between the two jaws of a vice, itself fixed on a heavy metallic bench. A dual force-acceleration sensor, Model 288D01, was installed between the damper rod and the shaker stringer.

Once the system is correctly installed in a vertical and stable position, the piston rod was driven vertically into a sinusoidal motion. The sensitivity range of the data acquisition system was set to $10.2(\mathrm{mV}) /\left(\mathrm{m} / \mathrm{s}^{2}\right)$ for the sensor acceleration channel, and $22.4 \mathrm{mV} / \mathrm{N}$ for the force channel. The signal generator was set to generate a sine wave with $3 \mathrm{~V}$ amplitude and send to an amplifier with $24 \mathrm{~dB}$ gain. During the testing, a continuous reading of the force and the acceleration was achieved, as illustrated in Figure 2.

\section{RESULTS AND DISCUSSION}

The ideal force vs velocity graph for viscous damper will be more like Figure 3(a). Due to the nonlinear behaviour of the fluid and the hysteresis effect in a real case, the below graph will have an approximate vertical elliptic shape as shown in Figure 3(b). Brigley et al. (2007) conducted an 
experimental investigation for the MR isolator damper. The investigation showed that the elliptic shape of the ordinary viscous damper in Figure 3(b) will tend to rotate clockwise when decreasing the MR fluid stiffness, by changing its excitation current. The damper hydraulic oil under study will follow the previous concept of the effect of fluid stiffness on generating the Force-Velocity graph.

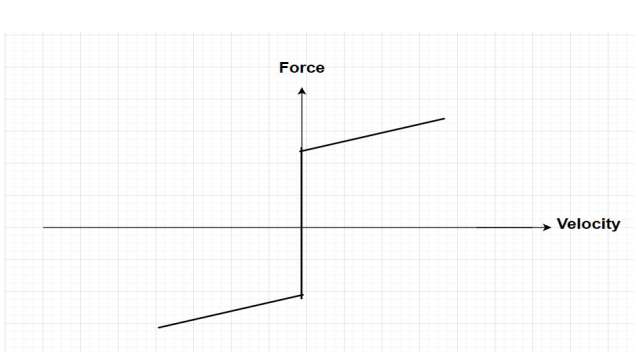

(a)

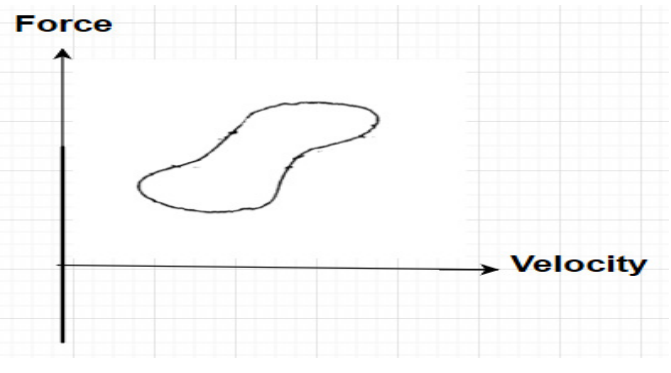

(b)

Figure 3: Force Vs Velocity of the viscous damper, (a) Non-Hysteresis (b) Hysteresis

In order to evaluate the damping coefficient of the modified fluid damper, different excitation frequencies were selected at the signal generator, starting from $1 \mathrm{~Hz}$ to $10 \mathrm{~Hz}$. At the lowest frequency, the damper will complete its extension and compression stroke with the full designed stinger/shaker stroke length. The results of the acceleration conducted from the sensor were numerically integrated, using MATLAB, to evaluate the corresponding velocity values. Figure 4 depicts the variation of force with respect to speed variation when the excitation frequency is $1 \mathrm{~Hz}$. One can see that the behavior of the damper is nonlinear, although the stroke length is too small $(2 \mathrm{~cm})$.

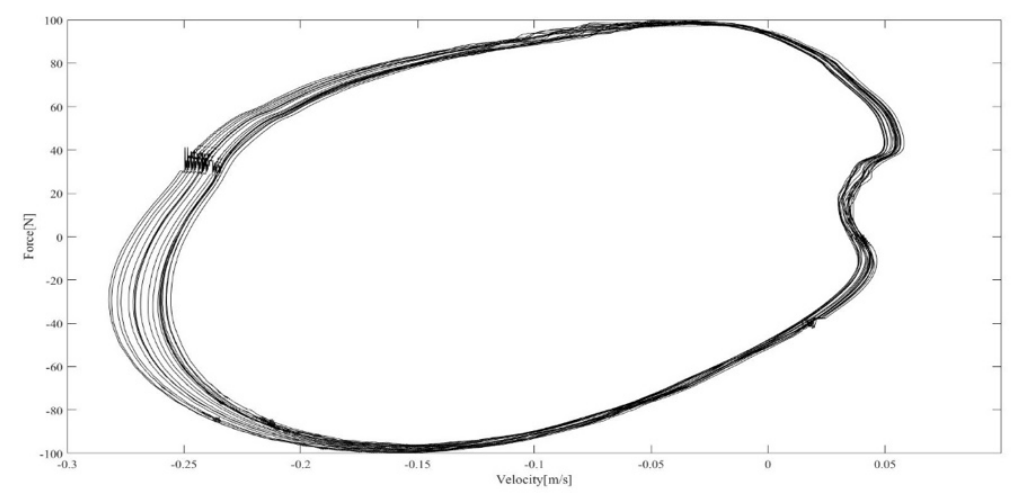

Figure 4: Force Vs Velocity of the piston rod at $1 \mathrm{~Hz}$ excitation frequency

The hydraulic oil stiffness is lower than the ordinary viscous damper oil. The low stiffness value tends to rotate the Force-Velocity graph clockwise with a small angle. The enveloped shape that described the extension and extraction process of the viscous damper piston is due to the hysteresis effect as illustrated above in Figure 4. The relation between the damping force and the motion velocity is usually represented by a linear equation, in the form of: 


$$
F=C V
$$

where $\mathrm{F}$ is the driving force, $\mathrm{V}$ is the moving velocity of the rod, and $\mathrm{C}$ is the damping coefficient.

Due to the nonlinear behaviour of the system, the calculation of the damping value $\mathrm{C}$, for each frequency, required a linear interpolation for the force-velocity graph data. After conducting such a procedure, the different values of $\mathrm{C}$ are shown in the following Table 2.

Table 2: Excitation frequency and damping coefficient values

\begin{tabular}{|c|c|}
\hline $\begin{array}{c}\text { Frequency } \\
(\mathbf{H z})\end{array}$ & $\begin{array}{c}\text { Damping Coefficient C } \\
\text { (N.s/m) }\end{array}$ \\
\hline $\mathbf{1}$ & 220 \\
\hline $\mathbf{3}$ & 290 \\
\hline $\mathbf{5}$ & 290 \\
\hline $\mathbf{8}$ & 530 \\
\hline $\mathbf{1 0}$ & 1100 \\
\hline
\end{tabular}

One can see that the damping value, which represents the overall interaction between the oil rheological properties and the damper internal design, is heavily dependent on the excitation frequency. At the range between 1 and $6 \mathrm{~Hz}$, the damping value is quasistable. However, starting from $7 \mathrm{~Hz}$, the amount of damping increases significantly, as shown in Figure 5.

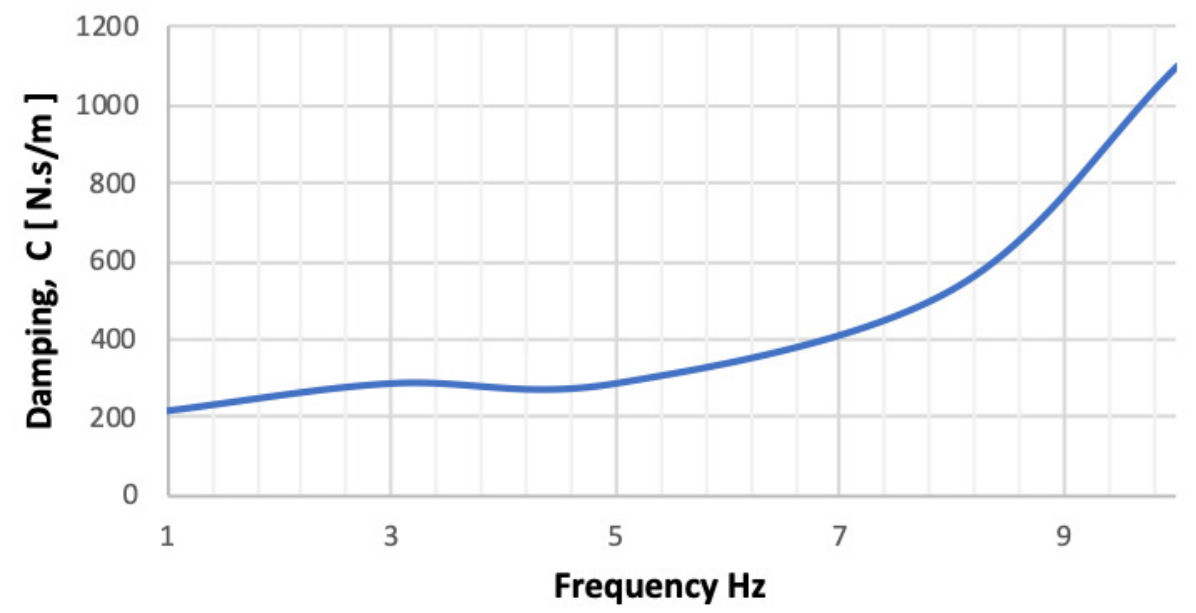

Figure 5: Damping coefficient vs excitation frequency

\section{CONCLUSION}

This research paper investigates the performance of a modified viscous damper excited by a sinusoidal force. The excitation frequencies were varied from 1 to $10 \mathrm{~Hz}$ while the force magnitude was kept constant at $440 \mathrm{~N}$. The experimental investigation led to the following conclusions:

1. Contrarily to what is commonly admitted, the damping coefficient is not constant. Indeed, the passage of the oil, the main cause for damping, through the piston head 
annular holes is a complex phenomenon that depends not only on the hole geometry but also on the type of oil (mainly its viscosity) and its flow across the piston holes.

2. The damping coefficient was found to be quasi-constant over a frequency range between 1 and $6 \mathrm{~Hz}$. Beyond that limit, a considerable increase is observed.

\section{REFERENCES}

Agrawal, A. K. \& Amjadian, M. (2015). In Innovative Bridge Design Handbook, chapter 20, Elsevier, The City College of the City University of New York.

Brigley, M., Choi, Y. T., Wereley, N. M. \& Choi, S. B. (2007). Magnetorheological isolators using multiple fluid modes. Journal of Intelligent Material Systems and Structures, 18(12), 1143-1148.

Iglesias, G. R., Ahualli, S., Echávarri Otero, J., Fernández Ruiz-Morón, L. \& Durán, J. D. G. (2014). Theoretical and experimental evaluation of the flow behavior of a magnetorheological damper using an extremely bimodal magnetic fluid. Smart Materials and Structures, 23(8).

Kaewunruen, S. \& Remennikov, A. M. (2008). New Research on Acoustics, chapter 5, Nova Science Publisher, New York.

Kemp, S. P. \& Linden, J. L. (1990). Physical and chemical properties of a typical automatic transmission fluid. SAE Technical Papers.

Li, K. \& Darby, A. P. (2006). An experimental investigation into the use of a buffered impact damper. Journal of Sound and Vibration, 291(3-5).

Rådeström, S., Ülker-Kaustell, M., Andersson, A., Tell, V. \& Karoumi, R. (2017). Application of fluid viscous dampers to mitigate vibrations of high-speed railway bridges. International Journal of Rail Transportation, 5(1), 47-62. 